\title{
Performatividades juvenis na cena urbana de Porto Alegre: Problematizações contemporâneas.
}

\author{
Angélica Silvana Pereira*
}

Resumo: Este artigo apresenta um recorte dos resultados de uma investigação sobre práticas juvenis que são espetacularizadas num espaço público de Porto Alegre/RS/Brasil, tomando-as como materialidades que possibilitam pensar a experiência de ser jovem na contemporaneidade. Busca-se mostrar alguns arranjos juvenis capazes desestabilizar as seguras definições sobre juventude que perduraram por longos anos, na direção de conhecermos as constelações móveis compostas por jovens nos mais variados cenários urbanos, enquanto sujeitos inscritos numa condição cultural de fortalecimento da cultura do consumo que incita e convoca os sujeitos a ousar, inovar, ser diferentes. Acredita-se que, ao mesmo tempo em que as práticas performativas exibidas por estes jovens são produzidas num contexto de hiperconsumo, são também capazes de fazer emergir subjetividades que escapam de modelos e prescrições sociais, desafiando-nos (re)pensar a política, a educação e a vida contemporânea.

Palavras-chave: Jovens; Práticas performativas; Corpo; Consumo; Subjetividade.

\begin{abstract}
This paper is part of the results of an investigation on youth practices performed in a public space in Porto Alegre/RS/Brasil. These practices are considered as materialities that make it possible to think the experience of being young today. The objective is to show some youth arrangements capable of destabilizing the safe definition of youth that has taken place for many years, therefore, it is possible to know the mobile constellations composed of youth in the different urban scenario, while subjects inscribed in a cultural condition of culture of consumption strengthening that encourage and convoke the subjects to risk, innovate, and to be different. It is believed that, while performative practices shown by these young people are produced in a hyperconsumption context, they are also capable of making subjectivities that escape from models and social prescription emerge, challenging us to (re)think politics, education, and life today.
\end{abstract}

Keywords: Youths; Performative practices; Body; Consumption; Subjectivity

\footnotetext{
* Mestra e Doutora em Educação pela UFRGS. Professora Adjunta do Centro de Educação da UFAL. http://www.ufal.edu.br/unidadeacademica/cedu
} 


\section{Performatividades juvenis na cena urbana de Porto Alegre: Problematizações contemporâneas.}

\section{Introdução}

Escolhi apresentar, neste momento ${ }^{1}$, algumas problematizações em torno de práticas juvenis urbanas exibidas aos domingos num dos principais parques de Porto Alegre/RS: O Parque da Redenção ${ }^{2}$. Procurei trazer fragmentos de cenas juvenis que venho acompanhando nos últimos anos, especialmente aquelas relacionadas à minha pesquisa de doutorado ${ }^{3}$, nas quais encontrei uma vasta e rica materialidade que me convocaram e ainda me convocam a pensar sobre a experiência de ser/estar jovem na contemporaneidade.

Como parte da metrópole, a partir da metade das tardes de domingo a Redenção é 'habitada' por centenas de jovens 'estranhos', que parecem poluir a busca da ordem normalizadora da cidade, através da performatividade de seus corpos. Devido ao grande fluxo de pessoas, o Parque torna-se um locus propício para as performatividades destes jovens, compondo uma instigante e inquietante cena urbana.

Estes jovens experimentam a metrópole, transitando, circulando, ressignificando espaços e fazendo recortes no tempo. Chamam atenção para si através do visual de seus corpos, de linguagens, de gestos, de performances capazes de desconcertar, incomodar e inquietar transeuntes. Misturando-se aos

\footnotetext{
${ }^{1}$ Este artigo foi produzido em virtude da mesa Juventude, política e subjetividade apresentada durante o Seminário Juventudes contemporâneas: rupturas, permanências e inventividades realizado na Universidade Federal de Alagoas em agosto de 2012. Desse modo, escolhi manter o tom oralizado da escrita que, na ocasião, serviu como roteiro da minha fala.

2 Localizado na zona central de Porto Alegre, é oficialmente chamado de Parque Farroupilha. Possui aproximadamente 40 monumentos, dentre eles o Monumento ao Expedicionário, o qual é também conhecido como "Arco" devido ao seu formato. Tombado em 1997, é um dos principais pontos turísticos da capital gaúcha. Aos domingos, funciona junto ao Parque uma feira de artesanato e de objetos antigos denominada Brique da Redenção. Durante o período de escravidão, o lugar onde hoje é o parque era um ponto de referência e de encontro para os escravos, tornando-se um lugar possível para algumas de suas práticas culturais. Foi lá que alguns alforriados se instalaram, quando não tinham para onde ir. No século XIX, logo após a 'libertação' dos escravos, foi batizado como Campos da Redenção, nome que mais tarde foi alterado para Parque Farroupilha. Neste estudo, optei não chamálo pelo nome oficial, e sim, Parque da Redenção [ou, simplesmente, Redenção], não somente pelo valor histórico e cultural pouco conhecido sobre a proveniência do seu nome popular, mas também porque ele é assim identificado pelos moradores da cidade. Aos domingos, torna-se um dos principais pontos de encontro e de lazer.

${ }^{3}$ Refiro-me à pesquisa Domingo no Parque: Notas sobre a experiência de ser jovem na contemporaneidade, a qual foi realizada de 2007 a 2011 junto ao Programa de Pós-Graduação em Educação da Universidade Federal do Rio Grande do Sul, sob orientação da $\operatorname{Prof}^{\mathrm{a}} \operatorname{Dr}^{\mathrm{a}}$ Elisabete Maria Garbin.
} 
fluxos de pessoas, de imagens, de veículos, de informações, buscam alternativas para serem vistos e constroem relações de afeto.

Neste contexto, a noção de performance me parece extremamente útil para analisar as práticas juvenis no Parque, tomando-as como parte de um espetáculo imagético que favorece (re)invenções de si, estéticas e afetivas e que requer um determinado desempenho desses sujeitos. A performatividade está relacionada, então, com desempenho dos jovens frente ao cumprimento das normas sociais que prescrevem comportamentos, tendo como foco o controle dos corpos e frente os desafios de bem como à capacidade que de construir uma imagem espetacular de si. (PEREIRA, 2011)

\section{No Parque...}

Gestos e linguagens se misturam. Espaços demarcados por grupos, nomadismos, drogas lícitas, drogas ilícitas, afetos, amizades, conversas, músicas, violões, namoro, ficadas picantes, pegação e desfiles de corpos... Diante dos olhos da cidade, o Parque se transforma em espaço privilegiado das expressividades juvenis.

Estas expressividades são compostas por uma infinidade de práticas juvenis capazes de causar múltiplas fraturas na tradicional compreensão sobre juventude, desestabilizando explicações e definições que desde o início do século XX têm nas características biopsicológicas as principais referências para explicar o que é ser jovem. Com efeito, por longo período a juventude foi definida como uma fase da vida determinada, sobretudo, por uma faixa etária correspondente a várias transformações biológicas e comportamentais, as quais antecedem a vida adulta.

Muitas dessas práticas têm na metrópole cenários extremamente favoráveis para as suas mais diferenciadas formas de produção e exibição. Como assinala Feixa (1998), desde o período do pós-guerra, a emergência da juventude tem redefinido mapas das cidades, de seus espaços e de seus tempos. Através de ações ou práticas coletivas, jovens tem ressignificado espaços urbanos esquecidos, transformando-os em seus territórios.

Em suas análises, Canevacci $(2004,2005 ; 2007)$ apresenta a metrópole comunicacional como uma possibilidade de olhar para as grandes cidades, pois nelas tudo comunica: os muros, as paredes, os corpos, as ruas, os sons, os automóveis... Elas são compostas por imagens materiais e imateriais como corpos, sons, ruídos e muito visual. São polifônicas, são policromas, são comunicacionais, porque fazem aparecer vozes diversas, cores e imagens múltiplas que compõem fluxos comunicacionais que favorecem a fluidez, a criação de brechas, de rachaduras que podem reconfigurar modos de existência. Assim, as metrópoles têm se constituído em territórios onde os jovens performatizam modos de 
Performatividades juvenis na cena urbana de Porto Alegre: Problematizações contemporâneas.

existência em e através de seus corpos nômades que habitam temporariamente espaços variados, muitos deles inusitados.

O Parque não é um território esquecido, nem mesmo inusitado. Em muitas cidades, são comuns aglomerações juvenis em espaços como praças e parques. Mas apesar de cenas como estas parecerem semelhantes, cada uma delas oferece pistas para pensar dinâmicas juvenis circunscritas em atmosferas culturais distintas.

$\mathrm{Na}$ Redenção, muitos jovens imaginam estar distantes de algumas formas de controle e das normas sociais, o que lhes 'autoriza' à determinadas práticas. Lá parecem viver uma espaçotemporalidade ${ }^{4}$ entre parênteses em relação às demais do seu cotidiano, regada a experimentações, fruições, performances, celebrações do momento.

Tentando algum distanciamento dos espaçostempos marcados pelo controle, caracterizados pelos compromissos escolares, familiares e do mundo do trabalho, estes jovens, atraem os olhares dos adultos e dos 'outros'. Afinal, o que leva tais jovens a estar daquele modo, publicamente no Parque, justamente no dia em que ele é mais frequentado? O que faz com que eles sejam adeptos a determinadas práticas que transgridem padrões ou modelos de estética e de comportamento?

Se nos aproximarmos do pensamento de Foucault (1979) nos depararemos com a questão da verdade. Para o filósofo, as verdades são construções e muitas delas funcionam como formas de regular e controlar a vida em todas as suas dimensões e estão circularmente ligadas aos sistemas de poder, que a produzem e a apoiam. Assim, tem-se discursos diversos produzidos em distintos espaços sociais - muitos deles reconhecidos e legitimados - que relacionados, entrelaçados e articulados, atuam em forma de rede. Através das redes discursivas, determinadas verdades são construídas sobre os sujeitos e as coisas.

Cada sociedade entende, acolhe e (re)produz determinados discursos como verdadeiros. Esses discursos 'verdadeiros' penetram, de diversas maneiras, em maior ou menor intensidade, os sujeitos que estão a eles submetidos. Neste sentido, parece pertinente olhar para as práticas de performativas dos 'jovens do Parque', como uma possibilidade de analisar como estes se relacionam com os regimes de verdade dos nossos tempos, tentando entender de que maneiras experienciam significados culturais e o conjunto de normas sociais que regem suas vidas.

\footnotetext{
${ }^{4}$ Alves (2006) propõe a escrita junta e invertida de alguns termos, dentre eles espaçotempo, para fazer um contraponto à maneira como são tradicionalmente tratados, mostrando que esse modo dicotomizado de compreendê-los inventados pela ciência moderna, não tem dado conta das reflexões contemporâneas sobre questões relativas à sociedade, à educação e a cultura. Assim, as expressões espaçotempo e espaçotemporalidade foram grafadas desse modo por partilhar do entendimento de Alves e também por concordar com outros autores que defendem que cada vez mais tempo e espaço têm suas fronteiras apagadas.
} 
De fato, ruas e parques causam a sensação de serem espaços menos institucionais que a família, a igreja, a escola, mas vale lembrar que eles estão submetidos a conjuntos de normas e de verdades que tentam organizar a vida social $^{5}$. A partir de tais premissas, vale refletir sobre possíveis estratégias juvenis para escapar às formas de controle. Seriam, então, os arranjos juvenis espetacularizados no Parque uma forma de escapar do controle aberta à novidade? As imagens juvenis exibidas poderiam ser vistas como formas de ruptura?

\section{A metáfora da mancha movediça}

Ao circular no Parque a partir da metade das tardes de domingo, pode-se assistir a composição gradativa de uma grande mancha escura que tem, em seus meandros, alguns pontos coloridos. Ela é composta por inúmeros corpos jovens que geralmente vestem roupas pretas e que são investidos de outros elementos visuais que os diferenciam dos demais frequentadores daquele espaço.

Estes corpos transitam por vários dos seus recantos, espalhando- se entre monumentos, árvores, bancos, banheiros e brinquedos dispostos pelo Parque. A mancha movediça tem um efeito visual que rompe com a linearidade imagética do Parque e suas configurações antes da chegada dos jovens. Mas para além daquilo que pode ser visível, através do olfato é possível identificar a mancha, pois os cheiros de cigarro, cerveja, álcool e em alguns pontos, o cheiro de maconha sinaliza que ela está próxima. Sua sonoridade também permite identificá-la, através da mistura de conversas, gritos, músicas cantadas/gritadas ao toque violão, gírias, expressões rápidas, risos, gargalhadas... É uma mancha móvel, cambiante, sonora e que tem um cheiro peculiar, mas que é acima de tudo, visual. Mancha para ser vista. Jovens para serem vistos.

Em questão de uma hora, o Parque torna-se outro... Ele parece um grande corpo que se traveste ao abrigar muitos outros corpos carregados de significados peculiares... Tal qual os corpos jovens que o 'habitam', a partir de um determinado horário, o Parque é 'vestido' de outras cores, outros acessórios, mostrando outras possibilidades de se configurar Parque.

\footnotetext{
${ }^{5}$ No sentido lato, instituição significa padrões de comportamento e processos, estáveis, válidos e constantes, num determinado grupo social. Geralmente, instituição é entendida como uma organização que é criada ou mantida por algum interesse econômico, político, governamental, social, educacional ou religioso. Como exemplos, pode-se citar os cartões de crédito, o casamento, a maternidade, a família, a democracia e capitalismo. Em sentido restrito, é um organismo vivo, advindo das necessidades e pressões sociais, valorizada pelo público interno e externo que se tornam dela dependentes, com identidade própria. Preocupada com os seus resultados, sua perenidade e guiada por uma missão. Disponível em: <http://administracao.tripod.com/texto7.htm>. Acesso em maio de 2009.
} 
Performatividades juvenis na cena urbana de Porto Alegre: Problematizações contemporâneas.

A mancha movediça se movimenta numa zona militarizada da metrópole, entre alguns ícones institucionais. Dentre eles, pode-se citar o Colégio Militar, uma espécie de catedral do conservadorismo brasileiro por onde passaram os principais chefes do regime militar do país ${ }^{6}$ como Costa e Silva, Emílio Médici, Ernesto Geisel e João Batista Figueiredo; um quartel localizado no mesmo prédio; o Monumento do Expedicionário, construído como honraria militar aos brasileiros da Segunda Guerra Mundial e um posto da Polícia Militar. Além disso, ele é o cenário habitual das cerimônias e de exposições militares. Há também duas igrejas e outras três escolas - uma de Educação Infantil e duas dos anos iniciais do Ensino Fundamental - na Avenida José Bonifácio, a via de acesso à principal entrada do Parque. Aos seus arredores está também uma das escolas estaduais mais antigas do Estado e parte da Universidade Federal do Rio Grande do Sul.

Magnani (2007), ao propor o circuito de jovens como categoria para olhar como estes se movimentam pela cidade, elaborou alguns desdobramentos. O pedaço seria um espaço intermediário entre o privado e o público. Seria um espaço intermediário entre a casa e outros espaços onde se desenvolve uma sociabilidade significativa e estável. Seria um espaço que é uma referência, um território. Já, a mancha é o resultado da relação que estabelecimentos e equipamentos 'guardam' entre si, sendo motivos para os encontros de seus frequentadores. Na perspectiva deste autor, ela está mais ancorada na paisagem do que nos seus usuários. A partir da oferta de determinados bens e serviços, vira ponto de encontro. Ela é mais aberta do que o pedaço, acolhe um fluxo maior de pessoas e seus frequentadores são eventuais. São áreas contíguas do espaço urbano dotadas de equipamentos que marcam seus limites e que "viabilizam uma atividade ou prática predominante. [...] Esta categoria foi proposta para descrever um arranjo espacial estável na paisagem urbana" (MAGNANI, 2007, p. 20). Há também o trajeto, que para o autor "aplica-se aos fluxos recorrentes no espaço mais abrangente da cidade e no interior das manchas urbanas." (MAGNANI, 2007, p.20). Trata-se de um deslocamento mais distante, por regiões não contíguas.

A mancha movediça é 'estável' no sentido de estar no Parque todos os domingo, mas não em relação a diversidade de práticas que ocorrem em seus meandros. Embora eu reconheça que algumas das características da mancha proposta por Magnani possam ser úteis enquanto categoria para analisar deslocamentos juvenis na metrópole, o sentido que proponho para mancha movediça no contexto do Parque é simplesmente imagético e metafórico. Trata-se de uma

${ }^{6}$ Os generais Costa e Silva, Emilio Médici, Ernesto Geisel e João Batista Figueiredo tiveram parte de sua formação militar neste estabelecimento centenário. Atualmente o Colégio Militar não se restringe a uma escola para os militares. O ingresso dos estudantes acontece mediante seleção pública e suas vagas são bastante concorridas por ser visto como uma instituição de qualidade que tem também como foco a construção da disciplina dos corpos. 
mancha que é composta principalmente pelos corpos dos jovens. Os sujeitos são a própria mancha. Ela também corresponde ao pedaço, já que é um espaçotempo de referência para muitos jovens. Além disso, é uma mancha móvel devido aos inúmeros trajetos que são desenhados dentro dela, esticando-a, movimentando-a, redesenhando-a, personificando-a.

Desse modo, a mancha movediça de que falo, é uma mistura de todas essas categorias. E como ela é uma construção imagética, ela tem seus meandros e seus entornos. Nos seus meandros estão práticas diversas que a demarcam como um território identitário e subjetivo de jovens que buscam se distinguir entre os demais, através de performances e transgressões, ou mesmo de performances transgressoras.

Isto, no entanto, só é possível porque nos entornos da mancha movediça, encontram-se famílias, crianças, adultos e também outros jovens, cujas práticas, aparentemente, não supõem a nenhuma transgressão: tomam chimarrão, conversam, fazem rodas de violão, namoram e seus corpos apresentam um visual e um comportamento socialmente aceitos e tidos como 'normais'. Os seus entornos, ou seja, aquilo que não está nela e que não é parte dela - os outros - são a condição para a sua existência.

Devido aos seus entornos, a mancha movediça pode se construir a cada domingo, através da performatividade dos corpos jovens. Transformados, os corpos dos jovens compõem uma mancha movediça que nunca ganha os mesmos contornos. Os pequenos coletivos dos grupos juvenis que se reúnem no Parque, são montantes da mancha. Um público diverso, formado pelos frequentadores do Parque e pelos próprios jovens performers, já que, neste espetáculo, as buscas pela visibilidade implicam numa dinâmica que já não basta o olhar dos 'de fora'. É preciso, cada vez mais, ser visto e ser reconhecido pelos próprios pares; para assim, constituir a si mesmo como sujeito único. Em suas singularidades, estes corpos misturam-se compondo um aglomerado de múltiplas imagens...

\section{Jovens performers}

A preparação quase ritualística para a cena domingueira envolve atividades como marcar com os amigos, juntar dinheiro para o transporte e para a bebida que será consumida, trocar mensagens pela internet durante a semana falando sobre o encontro de domingo, elaborar e investir na montagem de um visual, preparar músicas para serem partilhadas e encontrar estratégias para ter o consentimento dos pais ou para burlar proibições.

Outros investimentos tornam-se necessários para estes jovens, pois em meio a tantas performances, é preciso que cada um encontre as suas estratégias de visibilidade. Estas estratégias levam em conta alguns aspectos: é preciso ser do grupo, pertencer, mesmo que seja através de compartilhamentos culturais 
Performatividades juvenis na cena urbana de Porto Alegre: Problematizações contemporâneas.

mínimos; é preciso também ter a sua singularidade, para que cada um tenha o seu reconhecimento numa coletividade. Geralmente, esta singularidade é expressa através da aparência dos corpos. Ortega (2006) enfatiza que "A aparência do corpo tornou-se central às noções de auto identidade. $\mathrm{O}$ corpo veio representar a liberdade pessoal, o melhor de nós" (ORTEGA, 2006, p.46).

A montagem de looks juvenis para ir ao Parque implica em vestimentas, penteados, usos de acessórios, maquiagens e outros símbolos cujo valor comunicativo tem sempre uma relação com um modo de estar no Parque, como, um jeito de falar, modos de circular, bem como com os lugares onde os jovens individualmente ou em coletivos menores se instalam momentaneamente e, principalmente com quem e para quem realizam tais investimentos. Vale transgredir padrões estéticos e comportamentais para ser visto e reconhecido. Por isso, algumas práticas de transgressão são ao mesmo tempo performativas, na busca de reconhecimento ante os demais jovens, como também provocando algum mal-estar frente os frequentadores e passantes.

Um olhar panorâmico lançado à mancha movediça pode inferir que os jovens que a compõem parecem ser/ estar muito iguais. Conforme referi anteriormente, usam na sua maioria, roupas pretas, coturnos, botas, acessórios parecidos, tatuagens, piercings, penteados e cores diversas nos cabelos, etc. Entretanto, há diferenças que são postas em evidência através de pequenos detalhes das suas vestimentas, dos modos como usam determinados acessórios e/ou o cabelo, ou mesmo pelos usos de gírias, de gestos, e, principalmente, pelo gosto musical.

Mesmo nesse emaranhado de coletivos menores, onde a identificação entre os grupos se dá através da marcação da diferença, cada um tenta atribuir um sentido único a si mesmo através daquilo que pode ser visível em e através do corpo. Os símbolos carregados nos corpos dos jovens são ambivalentes, incongruentes, polissêmicos, fendentes e são capazes de colocar em circulação significados e representações complexas sobre si mesmo e seus grupos culturais (PAIS, 2008a).

Entre os jovens as identificações são contingentes e esquivas nos seus processos de reconhecimento, na medida em que combinam uniformização e diferenciação, convergência e dissidência. As identidades de grupo emergem de identificações e contra identificações, de oposições e distinções fundando muitas vezes, uma espécie de terreno de confronto entre 'uns' e 'outros'[grifo da autora] (GARBIN, 2001). No jogo das identificações, os corpos dos jovens tornam-se um panorama, uma paisagem ambulante cujo objetivo é ver e ser visto. As pessoas olham pra mim e pensam: Ah, esse cara tem atitude em se vestir assim. O cara é foda! Eu sou reconhecido por essa questão, comentou um dos jovens no Parque.

Esse exercício de ver e ser visto assume uma dimensão fundamental nas práticas culturais de jovens contemporâneos, pois sem o espetáculo, sem esse reconhecimento vindo do olhar do outro, corre-se o riso de cair no anonimato. Num mundo em que a supremacia das imagens parece penetrar quase todos os 
espaços, a aparência dos corpos acaba se tornando uma realidade irrefutável e também a melhor pista para pensar as identidades (SONTAG, 2008). Na mesma direção, Pais (2008b) observa que "Existir também quer dizer ser percebido e reconhecido como distinto. Quanto mais negado, ignorado ou reprimido se é, mais necessário se torna afirmar a existência - para os outros e para si mesmo" (PAIS, 2008b, p. 217).

Para estar entre os seus pares e também entre os 'de fora' que compõe a mancha movediça no Parque, jovens ousam no visual portando em seus corpos sinais de identidade, de pertencimentos. Usar roupas pretas é quase uma regra entre os jovens da mancha, que simboliza a rebeldia para alguns deles, conforme mostram os fragmentos abaixo:

As composições corporais dos jovens são instrumentos de significação simbólica que dão visibilidade e por vezes, denunciam arranjos sociais de diferenças e discriminações de classe, étnicas e de sexualidade e outras. Se para alguns jovens, usar preto não tem um significado que vai além do gosto pela cor, para outros, o preto é um símbolo que tem o poder de estruturar a imaginação e proclamar ou emoldurar a desordem, a rebeldia e também a transgressão (PAIS, 2008).

Estar entre os de preto no Parque $e^{7}$ sugere estar entre jovens que transgridem no visual e em outras condutas. Pode-se ponderar que o preto é um elemento constitutivo da mancha movediça que permite conferir-lhe um caráter transgressor, já que o uso desta cor expressa uma vontade de distinção, de distanciamento social e um desejo de ruptura ante os demais jovens que lá estão, que se vestem 'normalzinho' e que são chegados em roupas de marca, como dizem alguns dos jovens. Ainda sobre isto, Pais (2006) observa que "A excentricidade no vestir, presente em muitos estilos juvenis, corresponde também a um questionamento da validade de limites convencionais" (PAIS, 2006, p. 16). O autor destaca ainda que os investimentos na imagem corporal contribuem para a construção da identidade dos jovens, conferem-lhe uma expressão simbólica de poder, uma vez que diferenciam-se entre si através de atributos distintivos, em que é preciso ser/estar igual, sendo/estando ao mesmo tempo diferente.

Em meio a estas buscas por visibilidade, os jovens são sujeitos performers, ou seja, um híbrido que faz do próprio corpo a arte, o espetáculo. Assim, chamo de jovens performers estes sujeitos por terem em seus corpos o principal locus de suas práticas performativas, as quais tem sido um misto de práticas de consumo e de práticas de transgressão capazes de colocar em exibição outras subjetividades.

Assim, entre tantos discursos e práticas que produzem os sujeitos, nas cenas do Parque pude identificar a emergência de outras subjetividades relacionadas à

\footnotetext{
${ }^{7}$ Expressão utilizada pelo público em geral para referir-se aos jovens da mancha movediça.
} 
Performatividades juvenis na cena urbana de Porto Alegre: Problematizações contemporâneas.

classe socioeconômica e à sexualidade sendo espetacularizadas e celebradas entre os jovens.

\section{Subjetividades em exibição}

A mancha movediça é composta por jovens vindos de diversos lugares cidades vizinhas, bairros distantes, zonas periféricas - e de diversas classes sociais, sendo crescente a participação de jovens pobres no espetáculo domingueiro. Para poder fazer parte do espetáculo, vale solicitar dinheiro para tios, avós, irmãos mais velhos, bem como inventar necessidades de gastos com materiais escolares; pedir dinheiro emprestado para amigos e pegar alguns trocados dos pais às escondidas.

Além de economizar durante todo o mês ou a semana inteira pra poder ir para a Redenção, é preciso pensar também em outras necessidades, afinal, a gente precisa ter um troco pra bebida. Quando alguém não tem grana pra ajudar na bebida, a galera se ajuda, comentou uma jovem em uma das nossas conversas. Ninguém deixa de se divertir porque tá duro, complementou um amigo da jovem que participava da conversa. Assim, o Parque acaba sendo uma alternativa de diversão garantida, já que, mesmo sem dinheiro, entre os pares tornam-se possíveis negociações para que ninguém deixe de compartilhar determinadas práticas.

Para estes jovens, estar na Redenção aos domingos implica em construir-se e tornar-se visível através de um fazer-se ver que favoreça o sentimento de pertença a um grupo e àquele lugar, àquela cena. Ir vestido 'normalzinho' consiste em produzir uma imagem de si que destoa das demais e que incorre no sentimento de estar de fora. Para sentir-se pertencendo, é necessário exibir algumas adesões identitárias. Estas adesões se dão através dos discursos que atribuem significados sobre o consumo de determinados produtos, lugares e comportamentos. Neste sentido, as próprias identidades, como ser roqueiro, ser emo, ser punk e outras, podem ser vistas também como uma questão de consumo.

Importa reconhecer que estes consumos identitários são sempre muito complexos: eles estão atrelados aos modos de subjetivação nos diferentes contextos da vida destes jovens, nos quais o consumo parece ter sempre uma posição central. Assim, os jovens são construídos através de discursos mercadológicos que provocam, incitam, convocam o permanente consumo como condição para ser, pertencer. "Suas vidas e suas subjetividades estão sendo crescentemente administradas no interior da governamentalidade neoliberal, orientada predominantemente para a movimentação e a gerência da economia do capitalismo tardio das sociedades globalizadas" (COSTA, 2008, p. 281).

Costa (2008) observa que, diante da lógica de que ninguém pode ficar fora do consumo, há modos de subjetivação globais, dirigidos a sujeitos com condições individuais muito diferenciadas. "E para que nenhum consumidor potencial seja 
desperdiçado, há versões de produtos adaptadas ao perfil de distintos grupos de sujeitos" (COSTA, 2008, p. 281), inclusive para grupos de baixa renda.

O 'normal' de ser jovem hoje é poder ter acesso a determinados consumos materiais e culturais. Sem eles, torna-se difícil pertencer, fazer parte. É preciso estar conectado, ter um celular, ouvir determinadas músicas, conhecer e freqüentar determinados lugares, usar algumas gírias e expressões da hora etc. Para Lipovetsky (2006), as últimas duas décadas do século XX têm sido caracterizadas pelo hiperconsumo, o qual é configurado pela relação cada vez mais forte entre a satisfação corporal e estética dos indivíduos, fundando uma nova relação emocional entre pessoas e mercadorias. As marcas se fortalecem e, no lugar da venda de produtos, vendem-se conceitos e estilos de vida, associados às marcas representadas por seus slogans de alcance global. Para o autor, o hiperconsumo manifesta-se pela crescente ansiedade pelo consumo, criando a necessidade de consumir como uma forma de lidar com as tristezas e frustrações.

Rocha (2006) assinala que o consumo, seja no plano das narrativas e/ou no plano das práticas, perpassa a vida social com uma força que poucos fenômenos têm, por ser dotado de uma capacidade de afetar a vida dos sujeitos. Ele assume uma posição proeminente e é capaz de estruturar valores e práticas que regulam relações sociais, de definir mapas culturais e de construir identidades.

Entretanto, muitos dos jovens espetacularizados no Parque passam por alguns tipos de privações materiais que lhes impõem investimentos grandes para poder consumir e fazer parte da mancha movediça. Embora haja uma infinidade de produtos, serviços, conceitos que podem ser consumidos independentemente da classe socioeconômica, a classe socioeconômica ainda é um dos aspectos que interferem fortemente na marcação da diferença entre os sujeitos. À ela, geralmente estão associados outros elementos, como etnia e gênero, os quais acabam por configurar-se em operadores subjetivos importantes.

Para grande parte das instituições, 'a juventude' corresponde a um importante momento de inserções sociais, como escolhas profissionais, ingresso ao mercado de trabalho, acesso a determinados consumos e a espaços de lazer e diversão, etc. Há também a compreensão de que 'a juventude' é uma fase de inconformismo frente a ordem social vigente, em que a pobreza e a falta de perspectivas pode transformá-la em agente e vítima de violência.

Torna-se necessário desnaturalizar comportamentos atribuídos aos pobres e aos ricos, buscando entender que os pertencimentos de classe são, pois, construções culturais que posicionam socialmente os sujeitos, inventando lugares a serem ocupados por eles, os quais são moldados nas redes de poder de uma sociedade.

Em muitos momentos, a Redenção foi narrada como uma das poucas opções acessíveis para que estes jovens pudessem deixar de lado o tédio domingueiro. Morar num lugar que não tem nada pra fazer; ficar livre do Programa do Faustão são 
Performatividades juvenis na cena urbana de Porto Alegre: Problematizações contemporâneas.

fragmentos de falas de alguns deles que me levam a inferir sobre a dificuldade de acesso a outras possibilidades de lazer, como TV a cabo, cinema, ou mesmo a internet.

As condições socioeconômicas repercutem nos modos de vida dos sujeitos, na maneira como são narrados, como são vistos e também em como eles mesmos aprendem a ver-se, narrar-se. A própria duração do tempo de vida que socialmente é denominado como juventude pode ser mais ou menos favorecida pelas características socioeconômicas dos jovens, tais como a renda familiar e o nível de desenvolvimento da região onde vivem.

Privações básicas ou mesmo de outra ordem, habitualmente consideradas supérfluas atuam como operadores subjetivos, já que os sujeitos imersos nestes contextos, além de viverem cotidianamente em condições sociais tidas como insuficientes para uma vida feliz e saudável, são posicionados nesses lugares e muitas vezes são ali fixados. Tentativas de trânsito fora do seu 'território' pode ser entendida como desordem, uma ameaça...

Os corpos são marcados por estas privações, produzindo determinadas experiências que têm no horizonte o desejo de uma juventude que pode transitar em espaços sociais diversos, que pode consumir determinados produtos, que pode viver prazeres como viajar, ir para a balada, ver shows de bandas favoritas, usar determinadas grifes. Assim, as marcas da exclusão estão intimamente ligadas às marcas que diferenciam os sujeitos uns dos outros e, ao mesmo tempo, instituem formas de homogeneização e normalização. Tendo como referência Foucault (1987; 2001), entendo a normalização como um processo pelo qual se elege de forma arbitrária uma identidade que passa a ser a referência, o modelo que muitas vezes se institucionaliza. Este modelo identitário torna-se 'normal' na medida em que contempla determinadas estéticas e determinados comportamentos e serve como parâmetro para considerar como desviante ou 'anormal' os sujeitos cujas identidades não se compatibilizam com estes modelos.

Assim, por mais que o consumo torne-se alcançável a todos, independentemente da classe social, cabe-nos prestar atenção nos esforços, empenhos e investimentos requeridos para que sujeitos de diferentes classes sociais possam ter alguns acessos e trânsitos parecidos. Suponho que os investimentos necessários para que um jovem de classe média/alta esteja na Redenção aos domingos é bastante diferenciado daquele jovem que precisa economizar a semana inteira para ser visto. Assim, jovens que carregam consigo as marcas de exclusões fabricadas socialmente, em especial, aquelas relacionadas à classe socioeconômica, possivelmente lidam de formas diferentes com as características colocadas como desejáveis e esperadas para a juventude dita 'normal'.

No contexto dos jovens da Redenção, alguns investimentos parecem fundamentais para que estes sintam-se pertencendo ao universo juvenil desses 
tempos. Por outro lado, há momentos em que as diferenças de classe são minimizadas, que fronteiras são matizadas, na medida em que o simulacro está disponível e acessível e já não importa mais se o produto é verdadeiro ou falso. Como observa Canevacci (2007), as pessoas compram produtos sabendo que ele pode ser falso, mas sabem também que ele tem uma "capacidade comunicacional verdadeira" (CANEVACCI, 2007, p. 73). Entretanto, a cada dia, a cada minuto, tem um novo produto no mercado, um novo lugar para conhecer, um novo esporte para praticar, uma nova banda para ouvir, um novo conceito para comprar, lembrando-nos dos empenhos necessários para poder dar conta das demandas que se impõem para sermos sujeitos desses tempos.

O que me parece estar nas entrelinhas dessas práticas é a proeminência de uma lógica neoliberal burguesa que, não raras vezes, nos inculca o que é esteticamente aceitável, que produtos devem ser consumidos, o que deve estar na moda, para que todos, independentemente da classe social, tenham novos desejos e novas necessidades de consumo. Assim, o consumo está de tal forma incrustado nas sociedades capitalistas contemporâneas que seu impacto nas vidas das crianças e jovens parece não causar nenhum tipo de preocupação. (COSTA, 2006, p.181)

Outra prática que tem sido cada vez mais espetacularizada no Parque é a pegação. A expressão pegação é parte do amplo e multifacetado arsenal comunicativo dos jovens do Parque. Seguida do sufixo "ção", que significa ação, processo ou resultado de uma determinada ação, pegar é fazer aderir, colar, grudar, agarrar, segurar, tomar posse. Colar para descolar, grudar para desgrudar. Segurar brevemente. Tomar posse por instantes. Surpreender, chegar a tempo de estar presente...

A pegação e o ficar parecem atividades complementares e indissociáveis. $\mathrm{O}$ que justifica a expressão pegação é o ficar/pegar vários ou várias num curto intervalo de tempo, ou seja, ter uma performance cujo desempenho resulta numa contabilização das ficadas. Entre os jovens, há o consenso de que a pegação implica em ficar. Entretanto, não há consenso sobre o que é ficar. Seu significado varia desde o beijo na boca, às carícias e à relação sexual propriamente dita.

Ficar e pegar são uma espécie de brincadeira onde todo mundo fica com todo mundo, uma declaração explícita de que ninguém é de ninguém. Aqui todo mundo já pegou todo mundo! Eu já peguei ela, [comentou uma jovem apontando para uma amiga do grupo], já peguei ele [indicando um amigo]... Já peguei a minha melhor amiga! comentou uma garota que estava com o grupo com quem parei para conversar.

Circulando no interior da mancha movediça, pude constatar que a pegação foi uma das práticas mais acionadas. Muitos dos jovens quando perguntados sobre os motivos pelos quais frequentam a Redenção citaram o ficar. Ficar não é uma prática recente entre os jovens. Enquanto prática, o ficar - especialmente no contexto da Redenção - ganhou novas configurações. 
Performatividades juvenis na cena urbana de Porto Alegre: Problematizações contemporâneas.

A primeira delas é um deslocamento da noite para o dia. Ir na Redenção aos domingos à tarde para ficar pode ser menos complicado do que sair à noite ou ir para a balada. Muitos dos jovens que compõem a mancha movediça ainda não completaram dezoito anos. Nesse caso é mais fácil driblar os pais para ir à Redenção à tarde do que conseguir sair à noite. Existe também o aspecto econômico. É muito mais barato ir pra Redenção do que pra balada, comentou um grupo de jovens. Aqui a diversão é garantida porque é onde tá todo mundo.

Outra reconfiguração do ficar é possibilidade de experimentações homoafetivas. Na mancha movediça, as práticas homoafetivas são comuns entre garotos e garotas, considerando-se ainda que, no clima da pegação, o que vale é variar de parceiros. As ficadas mais astuciosas são entre jovens do mesmo sexo ou aquelas com mais de um parceiro e/ou parceira ao mesmo tempo.

Entre as diferentes formas de entender e praticar o ficar, torna-se inegável que o beijo é demonstração mais acionada. Se beijou, mesmo sem ter transado, já dá pra dizer que ficou. No cômputo geral da pegação, beijar já indica um ficar. Para Almeida e Tracy (2003), "Nos regimes que compõem as novas semióticas afetivas em torno do ficar, o beijo assume a condição de performance, de intransitividade, fisicalidade, arma corporal, descarga rápida da emoção. Princípio e fim. Ubiqüidade do ato" (ALMEIDA; TRACY, 2003, p. 137).

Mesmo sabendo-se que o beijo é uma demonstração de afeto e de sexualidade socialmente aceita e menos reprimida em espaços sociais, através dele pode-se inferir que o ficar acaba sendo espetacularizado. Vale ressalta que muitos jovens adotam a pegação ou o ficar motivados pelo desejo de prazer, de diversão, pela vontade de experimentar, para chamar atenção.

Assim, ficar sugere uma dimensão lúdica e frouxa à relação, capaz de proporcionar aos jovens diversão e descontração, por ser entendida como uma modalidade de interação afetiva caracterizada por uma suposta superficialidade e pela ausência de compromisso nas relações. É uma prática acionada basicamente por encontros velozes e fugazes de jovens em que "corpos atravessam o espaço de forma seriada, produzindo a maior acumulação possível de imagens de alto impacto por unidade de tempo e, paradoxalmente, baixa quantidade de informação por unidade de tempo" (ALMEIDA; TRACY, 2003, p.137). Este aspecto extremamente fugaz das relações amorosas desses tempos remete ao que Bauman (2004) chamou de amor líquido, referindo-se à extraordinária fluidez destas relações que se movem e escorrem sem muitos obstáculos e que são marcadas pela ausência de solidez.

Desde muito tempo, ser jovem significa namorar, agora ficar. Namorar é serio. Ficar é mais permissivo. Se por um lado, os jovens preferem as interações afetivas do ficar, devido a fluidez dos acordos, principalmente, no que tange aos compromissos do namorar, por outro, muitos adultos consideram que o ficar configura-se num tipo de relacionamento que desqualifica alguns valores que 
fazem parte a amorosidade entre homens e mulheres (ABRAMOVAY; CASTRO; SILVA, 2004). Muitos adultos desconhecem os acordos - explícitos ou não envolvidos no ficar e na pegação. Para muitos adultos e para outros jovens, as trocas interativas do ficar são associadas à promiscuidade e à moral. "Na crítica adulta e de muitos jovens ao ficar há uma desqualificação das relações sem compromisso dos jovens, uma atribuição de excessos e uma codificação de permissividade às práticas que não se enquadram no considerado padrão" (ABRAMOVAY; CASTRO; SILVA, 2004, p.96). Assim, geralmente, as falas no que concernem a sexualidade recaem em pares binários como: certo /errado; prazer/responsabilidade; saúde/doença.

Parece que a espetacularização do ficar entre os jovens tem sido um modo exercer a sexualidade, na qual, talvez mais do que prazer do beijo ou das carícias ou mesmo do sexo, há o prazer de estar sendo ou de poder estar sendo assistido. Podemos inferir que nas práticas de pegar e/ou ficar, é produzido aquilo que Ball (2010), em outro contexto, chamou de "um estado de permanente e consciente visibilidade" (BALL, 2010, p. 40) em que os apelos por uma sexualidade cada vez mais exibida exaltam a adrenalina e o perigo, componentes acionados nas praticas juvenis da atualidade, como se vê também nos esportes radicais, na pichação e nas transgressões a normas, leis e a outras formas de controle exercido pelos adultos.

Há também outros deslizamentos do ficar enquanto prática. Se em muitos contextos, o ficar são pequenos eventos que iniciam com o olhar até a contiguidade dos corpos e a materialização do beijo, o ficar da pegação na Redenção nem sempre cumpre tal ritual. Muitas vezes ele é prático, rápido, sem jogos de sedução. É mais para ser visto e contabilizar do que para conquistar. Pegar muitas garotas e/ou garotos confere aos jovens um reconhecimento perante seus pares.

Esse modo de viver os afetos e a sexualidade assume um caráter transgressor, na medida em que parece ir na contramão do amor romântico que aprendemos a viver ao longo dos anos. Giddens (1993) observa que a ideia do amor romântico está relacionada com aspectos como a criação do lar, a modificação nas relações entre pais e filhos, e a própria invenção da maternidade. Todos estes elementos foram integrantes do amor romântico, e afetaram homens e mulheres, alterando o papel e o status da mulher na família.

Como norma de conduta afetiva, o amor romântico se instalou na Europa, respondendo aos anseios de autonomia e felicidade pessoais inequivocamente criativos e enriquecedores. Sua estreita ligação com a vida privada burguesa o transformou em um elemento de equilíbrio indispensável entre o desejo de felicidade individual e o compromisso com os ideais coletivos. De acordo com Giddens (1993), desde o século XVIII, o amor romântico foi [e ainda é] o modelo predominante de relacionamento entre homens e mulheres nas culturas ocidentais. É nele que se sustenta o casamento monogâmico e a família nuclear, 
Performatividades juvenis na cena urbana de Porto Alegre: Problematizações contemporâneas.

subentendendo fidelidade mútua, atração sexual e a intenção de construção e manutenção de uma família.

No caso dos jovens da Redenção, há uma 'escancaração' da afetividade e da sexualidade, quando algumas práticas são postas em evidência do mesmo modo como se monta uma vitrine. São cenas de carícias e de masturbação com parceiros do sexo oposto ou do mesmo sexo para serem vistas, rompendo com significados mais conservadores sobre a vida afetiva-sexual. Se, por um lado, a manutenção da ordem social pode ser garantida através da conservação de determinados comportamentos alimentando e cultivando significados atribuídos a eles, por outro, esta ordem pode ficar ameaçada frente a comportamentos adversos, não só capazes de fraturar significados culturais tidos pelos jovens como tradicionais e conservadores, mas de alterar e colocar à mostra outros significados.

Nessa direção, a vida afetiva de tais jovens possivelmente esteja sendo cada vez menos pautadas na idéia do "amor para sempre" ou em representações idealizadas sobre amizade, amor, casamento, namoro, criando outras alternativas de vivência e de experimentação afetiva e sexual. As performances dos jovens no Parque, indicam um ruptura com esta heteronormatividade ${ }^{8}$, através da pegação entre jovens do mesmo sexo, mexendo com as representações idealizadas do casal heterossexual, amoroso, apaixonado e feliz.

Tais representações entram em choque com as práticas homoafetivas dos jovens no Parque, por alguns motivos. Primeiro porque não é preciso amar, menos ainda namorar e/ou casar para ficar [leia-se beijar, 'transar', etc.]. Segundo porque o caráter extremamente efêmero conferido ao ficar somado a uma contabilização desta prática vai à contramão das relações duradouras. Terceiro, por acionar possibilidades de viver estas relações efêmeras por puro prazer do momento. Quarto, por poder viver ou simplesmente experimentar todos os aspectos acima citados com parceiros do mesmo sexo, abandonando a supremacia da heteronormatividade.

As práticas performativas dos jovens do Parque têm mostrado que, se por um lado ainda segue vigente no imaginário das pessoas o ideário do amor

\footnotetext{
${ }^{8}$ Sobre a heteronormatividade, vale a pena retomar a noção de Louro (2005): refere-se a produção e reiteração compulsória da norma heterossexual e seu status de normalidade e, o que ainda é mais forte, seu caráter de naturalidade Nessa lógica, supõe-se "que todas pessoas sejam (ou devam ser) heterossexuais - daí que os sistemas de saúde ou de educação, o jurídico ou o mediático sejam construídos à imagem e semelhança desses sujeitos. São esses sujeitos que estão plenamente qualificados para usufruir desses sistemas ou de seus serviços e para receber os benefícios do estado. Os outros, que fogem à norma, poderão, na melhor das hipóteses, ser reeducados, reformados (se for adotada uma ótica de tolerância e complacência) ou serão relegados a um segundo plano (tendo de se contentar com recursos alternativos, restritivos, inferiores), quando não são simplesmente excluídos, ignorados ou mesmo punidos" (LOURO, 2005, p. 5).
} 
romântico, para muitos jovens as relações afetivas no Parque são mais uma forma de contestar tal modelo. Atualmente, as relações afetivas instantâneas entre os jovens do Parque supõem certa igualdade de gênero e dão visibilidade às possibilidade de exercer uma sexualidade homoafetiva, como uma espécie de afrontamento perante modelos hegemônicos e heteronormativos. A negociação entre os jovens passa a ser uma condição para tais relacionamentos, ao passo que no amor romântico, o modelo já está posto e se baseia em determinadas normas sociais. Isto significa que os modelos de controle empenhados em retardar a chamada iniciação sexual não estão mais funcionando, ou pelo menos, parecem menos eficientes.

Ao desenvolver a pegação com todo mundo: guria com guria, guri com guri, guria com guri, os jovens mobilizam concepções, sentimentos, crenças, valores e sensações inculcados em nossas vidas e tidos como principal referência para nos construirmos enquanto sujeitos. Mesmo trabalhando com a idéia de que nos dias de hoje há, de um modo geral, um afrouxamento das relações, a prática da pegação, especialmente entre jovens do mesmo sexo, expressa outras possibilidades afetivas e de sexualidade que rompem com modelos consagrados das identidades de gênero e de sexualidade, produzindo e exibindo outras subjetividades.

\section{Uma breve 'costura'}

As práticas performativas dos jovens no Parque parecem ratificar a ideia de perda irreversível da dimensão de exatidão da palavra juventude, apresentandonos uma insuportável ambivalência que abala nossas necessidades e nossos desejos de solidez de verdade. Os jovens que conhecemos hoje deslizam sobre as pretensões de verdade dificultando nossas tentativas de nomeá-los, classificá-los, fixá-los.

São jovens que, ao mesmo tempo em que experimentam uma lógica de exacerbação do consumo, também exibem subjetividades inversas aos modelos de ser jovem que buscam promover a moral, os bons costumes, a ordem. Estas subjetividades [como aquelas relacionadas à classe socioeconômica e à sexualidade aqui apresentadas] funcionam como formas de ruptura com modelos e processos homogeneizantes.

Assim, nas práticas performativas dos jovens no Parque, parecem coexistir um misto de significados que são pautados nas complexas características dos nossos tempos. Dentre estas características estão as incessantes incitações da cultura do consumo e a criação de alguns imperativos contemporâneos, fazendo com que a performatividade, para além de ser apenas um indicativo do desempenho do e no espetáculo, passa a ser também uma forma de produção dos sujeitos e dos seus papéis sociais (PEREIRA, 2011). Nessa direção, podemos pensar em modos de subjetivação que operam na contramão das práticas confessionais em que o sujeito mergulhava para dentro de si mesmo. São processos que tem na 
Performatividades juvenis na cena urbana de Porto Alegre: Problematizações contemporâneas.

visibilidade sua principal referencia, tanto para a produção, quanto para a circulação de subjetividades.

Não há dúvidas que as práticas juvenis, como aquelas observadas e analisadas em minha pesquisa, necessitam de olhares menos empenhados em demonizá-las, e mais sensíveis para problematizá-las. Afinal, são práticas que nos desafiam a (re)pensar a política, a educação, a vida. Olhar para os jovens mais estranhos a nós, com quem pouco, ou quase nada conseguimos traçar interlocuções; enxergar que há, em suas práticas tidas como 'absurdas e excessivas', um potencial capaz de fazer emergir outras subjetividades, pode nos levar ao acontecimento, à novidade.

\section{Referências}

ABRAMOWAY, Miriam; CASTRO, Mary Garcia; SILVA, Lorena Bernadete. Juventudes e sexualidade. Brasília: UNESCO Brasil, 2004.ALMEIDA, Maria Isabel Mendes; TRACY, Kátia Maria de Almeida. Noites nômades: espaço e subjetividade nas culturas jovens contemporâneas. Rio de Janeiro: Rocco, 2003.

ALVES, Nilda. Escola e cultura contemporânea - novas práticas, novas subjetividades, novos saberes: em torno de artefatos culturais. In: SOMMER, Luis Henrique; BUJES, Maria Isabel Edelwiess (orgs). Educação e cultura contemporânea: articulações, provocações e transgressões em novas paisagens. Canoas: Ed. ULBRA, 2006, pp. 163-175.

BALL, Stephen J. Performatividades e Fabricações na Economia Educacional: ruma a uma sociedade performativa. Educação e Realidade. Porto Alegre: Universidade Federal do Rio Grande do Sul/ Faculdade de Educação, n.2, v.35, p. 37-55, maio/ago 2010.

BAUMAN, Zygmunt. Amor líquido: sobre a fragilidade dos laços humanos. Rio de Janeiro: Jorge Zahar Ed., 2004.

CANEVACCI, Massimo. A cidade polifônica: ensaio sobre a antropologia da comunicação urbana. São Paulo: Studio Nobel, 2004.

CANEVACCI, Massimo. Culturas eXtremas: mutações juvenis nos corpos das metrópoles. Rio de Janeiro: DP\&A, 2005.

CANEVACCI, Massimo. Entrevista com Massimo Canevacci. Revista Sextante. Faculdade de Biblioteconomia e Comunicação da UFRGS, pp. 66-80, dez, 2007.

COSTA, Marisa Vorraber. Paisagens escolares no mundo contemporâneo. In: SOMMER, Luis Henrique; BUJES, Maria Isabel Edelwiess (orgs). Educação e cultura contemporânea: articulações, provocações e transgressões em novas paisagens. Canoas: Ed. ULBRA, 2006, pp. 177-193. 
COSTA, Marisa Vorraber. Cartografando a gurizada da fronteira: novas subjetividades na escola. In: ALBUQUERQUE JÚNUIOR, Durval Miniz; VEIGANETO, Alfredo; SOUZA FILHO, Alípio de (orgs.).Cartografias de Foucault. Belo Horizonte: Autêntica, 2008, pp. 269-294.

FEIXA, Carles. La ciudad invisible: territórios de las culturas juveniles. In: CUBIDES, Humberto J.; TOSCANO, María Cristina L.; VALDERRAMA, Carlos Eduardo H., (ed.). Viviendo a toda: jóvenes, territorios culturales y nuevas sensibilidades. Fundación Universidad Central, Santafé de Bogotá: Paidós, 1998, pp.83-109.

FOUCAULT, Michel. Os anormais: curso no Collège de France. São Paulo: Martins Fontes, 2001.

FOUCAULT, Michel. Vigiar e punir: nascimento da prisão. Petrópolis: Vozes, 1987.

FOUCAULT, Michel. Microfísica do poder. Rio de Janeiro: Editora Graal, 1979.

GARBIN, Elisabete Maria. www.identidadesmusicaisjuvenis.com.br - Um estudo dos chats sobre música da Internet. Porto Alegre: UFRGS, 2001. 260 f. Tese

(Doutorado em Educação) - Programa de Pós-Graduação em Educação, Faculdade de Educação, Universidade Federal do Rio Grande do Sul, UFRGS, 2001.

GIDDENS, Anthony. A transformação da intimidade: sexualidade, amor e erotismo nas sociedades modernas. Trad. Magda Lopes. São Paulo: Editora da Universidade Estadual Paulista, 1993.

LIPOVETSKY, Gilles. O império do efêmero: a moda e seu destino nas sociedades modernas. São Paulo: Companhia das Letras, 2006.

LOURO, Guacira Lopes. Heteronormatividade e homofobia: Notas para conferência de abertura do I Simpósio Paraná-São Paulo de Sexualidade e Educação Sexual, Araraquara, abril de 2005.

MAGNANI, José Guilherme Cantor. Introdução - circuito de jovens. In: Magnani, José Guilherme Cantor; SOUZA, Bruna Mantese (orgs). Jovens na Metrópole: etnografias de circuito de lazer, encontro e sociabilidade. São Paulo: Editora Terceiro Nome, 2007, pp. 15-22.

ORTEGA, Francisco. Das utopias sociais às utopias corporais: identidades somáticas e marcas corporais. In: ALMEIDA, Maria Isabel Mendes e EUGENIO, Fernanda (orgs). Culturas jovens: novos mapas do afeto. Rio de Janeiro: Jorge Zahar, 2006, pp. 42-58.

PAIS, José Machado. Buscas de si: expressividades e identidades juvenis. In: ALMEIDA, Maria Isabel de; EUGENIO, Fernanda. Culturas Jovens - novos mapas do afeto. Rio de Janeiro: Jorge Zahar Editor, 2006, Prefácio.

PAIS, José Machado. Máscaras, jovens e "escolas do diabo". Revista Brasileira de Educação, Vol. 13, no 37. Rio de Janeiro, Jan/ Abr.2008a.

PAIS, José Machado. Culturas de Grupo. In: LAGES, Mário Ferreira; MATOS, Artur Teodoro de (coords.) Recursos de Interculturalidade. Contextos e 
Performatividades juvenis na cena urbana de Porto Alegre: Problematizações contemporâneas.

Dinâmicas. Lisboa, Alto-Comissário para a Imigração e Diálogo Intercultural,

2008b, pp. 207-255. Disponível em: $<$ http://www.oi.acidi.gov.pt/docs/Col_Percursos_Intercultura/2_PI_Cap6.pdf>, acesso em agosto de 2011.

PEREIRA, Angélica Silvana. Domingo no Parque: Notas Sobre a Experiência de Ser Jovem na Contemporaneidade. Porto Alegre: UFRGS, 2011. 252 f. Tese (Doutorado em Educação) - Programa de Pós-Graduação em Educação, Faculdade de Educação, Universidade Federal do Rio Grande do Sul, Porto Alegre, 2011.

ROCHA, Everardo. Coisas estranhas, coisas banais: notas para uma reflexão sobre o consumo. In: ROCHA, Everardo; ALMEIDA, Maria Isabel Mendes de. EUGÊNIO, Fernanda. (orgs.). Comunicação, consumo e espaço urbano: novas sensibilidades nas culturas jovens. Rio de Janeiro: PUC- Rio: Mauad ed., 2006, pp. 15-34.

SONTAG, Susan. Ao mesmo tempo. São Paulo: Companhia da Letras, 2008.

OUTRAS FONTES CONSULTADAS

INSTITUIÇÃO. Disponível em:

$<$ http://administracao.tripod.com/texto7.htm>. Acesso em maio de 2009.

MONUMENTO DO EXPEDICIONÁRIO. Disponível em www.nosbairros.com.br. Acesso em 30 de março de 2008.

$\begin{array}{lllll}\text { PARQUE } & \text { da } & \text { Redenção. }\end{array}$ $<$ http://www.aredencao.com.br/imprensa0a.htm> e em $<$ www.briquedaredencao.com.br $>\mathrm{e}<\mathrm{http}: / / \mathrm{www}$.aredencao.com.br/ $>$. Acesso em 10 de abril de 2007. 